\title{
Correlation of PID and multiparity: a case control study
}

\author{
Shikha Pandey*, Ramesh Pandey
}

Department of Obstetrics and Gynecology, Bundelkhand Medical College, Sagar, Madhya Pradesh, India

Received: 04 February 2017

Revised: 09 February 2017

Accepted: 10 February 2017

\author{
*Correspondence: \\ Dr. Shikha Pandey, \\ E-mail: drshikhabmc2013@gmail.com
}

Copyright: () the author(s), publisher and licensee Medip Academy. This is an open-access article distributed under the terms of the Creative Commons Attribution Non-Commercial License, which permits unrestricted non-commercial use, distribution, and reproduction in any medium, provided the original work is properly cited.

\begin{abstract}
Background: Pelvic inflammatory disease (PID) has emerged as a silent killer that disturbs women's life. In the rural population of India, most women are usually not aware of symptoms of PID. They do not move for health care unless alarming symptoms develop. The objective of present study is to find out to find out correlation between PID \& multiparity.

Methods: The present study was conducted at Government Bundelkhand Medical College, Sagar. Study design: Case control, Participants: Females attending obstetrics \& gynecology department OPD, Sample size: Total 150 cases \& same number (150) of controls. Statistics: Chi - square test.

Results: The odds ratio (OR) was 0.69 with $95 \%$ confidence interval (CI) being $0.42-1.09$ for PID with multiparity as risk factor. Of 143 cases, multiparity was seen in 63 cases (44.05). In 150 controls, it was seen in 80 (53.33\%). The variation was not statistically significant $(\mathrm{p}=0.141)$. The Odds Ratio with in exepertise as a risk factor for PID was 2.41 with $95 \%$ CI being 1.78-3.27. Result shows etiological fraction of 58.5\% (CI 43.9-69.4\%) among inexpert hands. The delivery in untrained hands was significantly higher in cases (p 0.00001).

Conclusions: This study does not show multiparity to be a risk factor but delivery conducted by untrained hands was as a risk factor.
\end{abstract}

Keywords: Multiparity, PID, Untrained hands

\section{INTRODUCTION}

Pelvic inflammatory disease (PID) has emerged as a silent killer that disturbs women's life. In the rural population of India, most women are usually not aware of symptoms of PID. They do not move for health care unless alarming symptoms develop. As per definition, PID is the inflammation of the upper genital tract including the uterus, fallopian tubes, ovary, and the pelvic peritoneum. ${ }^{1,2}$

The disease, if left untreated, could result in serious complications such as infertility, ectopic pregnancies, chronic abdominal pain, and internal pelvic scarring. After abortion and delivery and during menstruation the natural protective mechanism of the genital tract is hampered. Besides these factors, intrauterine manipulations such as dilatation and curettage in abortion and manual removal of placenta lead to the entry and spread of pathogenic organism. IUCD is also a source of infection, especially when it is not introduced under aseptic conditions. Inflammation observed in PID patients result from infection mostly bacterial. ${ }^{1}$ The pathogens responsible that can be sexually transmittedare Chlamydia trachomatisneisseria gonorrhoea. ${ }^{3,4}$ Histopathology is the especific diagnostic investigation done in patients with PID. The endometrial biopsy has been studied extensively for the diagnosis of PID. Endometritis is definitive criteria for the diagnosis of PID. ${ }^{5}$ Endometritis is more common than myometritis 
and it, occurs in continuation with endometrium infections. Cervical inflammation is comparatively common and even some degree of cervix inflammation is present in virtually all parous women. The incidence of Salpingitis is more and keeps increasing. It might follow invasive procedure like D\&C or insertion of IUCD. Ovarian involvement causing Oophoritis usually spread from endometrium and always associated with tubal involvement. Pelvic infections are the most serious infections faced by women now a day. It is the commonest problem faced in infertility, legal abortions, family planning, postnatal and sterilization clinics in India and elsewhere. ${ }^{6}$ As per Centers for Disease Control(CDC), PID is a general term that refers to infection of the uterus, fallopian tubes and other reproductive organs. Pelvic inflammatory disease is the common and serious complication of some sexually transmitted diseases (STDs), especially gonorrhea and chlamydia. It can cause trauma to the fallopian tubes and tissues in and near the uterus and ovaries. If untreated, PID can cause serious consequences, including infertility, ectopic pregnancy, abscess formation and chronic pelvic pain. ${ }^{7}$ Pelvic infections are one or the most widespread and debilitating disease affecting women today. This case-control study was undertaken to know the correlation between PID and multiparity.

\section{METHODS}

The present study was conducted at Government Bundelkhand Medical College, Sagar.

\section{Cases selection criteria}

The Obstetric and Gynecology Department of Government Bundelkhand Medical College (BMC) Hospital has daily outpatients service. On an average daily outpatient at this OPD is 80-100 gynec cases per day, of which $8-10 \%$ have PID. In this study, one hundred fifty patients of PID who attended gynec OPD of BMC Hospital over a period of one year spread over February 2013 to February 2014 were selected with uniformly accepted criteria for PID as below:

- Lower abdominal Discomfort

- Profuse vaginal discharge

- Cervical movement tenderness leading to pain.

Cases meeting with the above diagnostic criteria were labeled as clinical cases of PID.

\section{Control selection criteria}

With respect to each case, a control was selected from women attending BMC Hospital OPD for any complaint, health problems other than obstetrics and gynecology. 150 (One hundred fifty) control were selected from general medicine outdoor input of BMC hospital. General Medicine OPD has remarkable input of patients in BMC which has served the purpose. The definition of the term multiparity was considered from available literature for the purpose of present study.

\section{Multiparity}

Women who are para three or more were labeled as multiparous women. For the purpose of evaluating the role of multiparity as risk factor, which might influence the pathogenesis of PID. Every patient was matched to a patient in the present group with a patient with respect to age (by 5 years age group). Average age in cases was $32.56 \pm 7.31$ and in controls was mean $32.58 \pm 8.05$. This difference was statistically not significant.

\section{Statistical analysis}

The complete information from the enquiry of cases and controls was coded and data fed into computer by using statistical software EPI-Info. ${ }^{8}$ The data was analyzed by Epi-Info. Significance of variation in the prevalence of Pelvic disease cases and controls due to multiparity was analyzed by using Chi-square.

\section{RESULTS}

Of the 143 cases, multiparity was present in 63 cases $(44.05 \%)$ and in 150 controls it was in 80 (53.33\%). This difference was not statistically significant $(\mathrm{p}=0.141)$.

Table 1: Age comparison.

\begin{tabular}{|l|l|l|}
\hline Age (yrs) & Cases & Control \\
\hline $16-20$ & 02 & 06 \\
\hline $21-25$ & 28 & 24 \\
\hline $26-30$ & 38 & 41 \\
\hline $31-35$ & 42 & 38 \\
\hline $36-40$ & 21 & 20 \\
\hline$>40$ & 19 & 21 \\
\hline
\end{tabular}

The OR for PID with multiparity as a risk factor was 0.69. $95 \%$ confidence interval (CI) was 0.42-1.09 (Table 2).

Table 2: Correlation between multiparity and PID.

\begin{tabular}{|l|l|l|l|}
\hline & Cases & Controls & Total \\
\hline Multiparity + & $63(44.05 \%)$ & $80(53.33 \%)$ & 143 \\
\hline Multiparity- & $80(55.94 \%)$ & $70(46.66 \%)$ & 150 \\
\hline & 143 & 150 & 293 \\
\hline
\end{tabular}

The delivery in itself is not a risk factor for PID but delivery in untrained hands is a risk factor. The Odds Ratio in untrained hands as a risk factor for PID was 2.41. $95 \%$ CI was $1.78-3.27$. It shows etiological fraction of $58.5 \%$ (CI 43.9-69.4\%) among untrained persons. Delivery in untrained hands was significantly higher in cases than in controls (p 0.00001) (Table 3). 
Table 3: To compare delivery assistance in cases and controls

\begin{tabular}{|l|l|l|l|}
\hline & $\begin{array}{l}\text { Deliveries } \\
\text { among cases }\end{array}$ & $\begin{array}{l}\text { Deliveries } \\
\text { among controls }\end{array}$ & Total \\
\hline $\begin{array}{l}\text { Trained } \\
\text { hands }\end{array}$ & $193(52.34 \%)$ & $282(72.69 \%)$ & 475 \\
\hline $\begin{array}{l}\text { Untrained } \\
\text { hands }\end{array}$ & $175(47.56 \%)$ & $106(27.31 \%)$ & 281 \\
\hline Total & 368 & 385 & 756 \\
\hline
\end{tabular}

Table 4: To compare place of delivery in cases and controls.

\begin{tabular}{|c|c|c|c|}
\hline & $\begin{array}{l}\text { Deliveries } \\
\text { among cases }\end{array}$ & $\begin{array}{l}\text { Deliveries } \\
\text { among controls }\end{array}$ & Total \\
\hline $\begin{array}{l}\text { In } \\
\text { hospital } \\
\text { deliveries }\end{array}$ & $165(45.96 \%)$ & $254(64.96 \%)$ & 419 \\
\hline $\begin{array}{l}\text { At home } \\
\text { deliveries }\end{array}$ & $194(54.04 \%)$ & $137(35.04 \%)$ & 331 \\
\hline Total & 359 & 391 & 750 \\
\hline
\end{tabular}

\section{DISCUSSION}

We used a standard proforma to collect delivery history. This study is a hospital-based case control study. As the cases as well as controls were taken from hospitals so other parameters like income, socioeconomic status, personal hygiene, etc. were similar because both cases and controls showed the same group of patients coming to the hospital. At first multiparity was thought to be a risk factor because:

- Multiple births cause infection in the birth passage.

- Due to repeated birth patient's general immunity is decreased

- Repeated deliveries lead to anemia and chances of infections are much more in anemic women

Odds Ratio for PID with multiparity as a risk factor was 0.69 . 95\% CI was $0.42-1.09$. Of 143 cases multiparity was seen in 63 cases $(44.05 \%)$. In 150 controls multiparity was seen $80(53.33 \%)$ cases. This variation was not statistically significant $(\mathrm{p}=0.141)$. The possible reason could be:

- During pregnancy, the high estrogen and progesterone hormones levels give protection against PID; similar to the protective effect seen due to oral contraceptive use.

- Multiparity decreases the frequency of sexual intercourse and sexual intercourse acts as a risk factor for PID. So, less chances of PID in multiparity. ${ }^{9,10}$

- Multiple deliveries mean multiple contacts with doctors, if infection was present then it would have been treated.
- Infection in the fallopian tubes (salpingitis) can cause adhesions or complete tubal blocked. Thus, ectopic pregnancy or infertility may occur. For example, in a study of 415 women in sweden with a history of PID $21 \%$ had infertile as compared with $3 \%$ in a group with no history of PID. ${ }^{11}$

A study done by Beerthuizen found that nulliparous women are not at higher risk of PID than multiparous women. $^{12}$ A longitudinal study conducted by Wright demonstrated no relationship between the parity and the development of PID. ${ }^{13}$ In itself delivery is not a risk factor for PID but delivery in untrained hands is a risk factor. Though, the data between in hospital delivery and at home delivery is separated, the importance of delivery by trained personal cannot be ignored. Hens, we analyzed the data and compared delivery by trained and untrained personal. Odds Ratio with untrained hands as a risk factor for PID was 2.41. 95\% CI was 1.78-3.27. Result shows etiological fraction of $58.5 \%$ (CI 43.9-69.4\%) among untrained persons. Delivery by untrained personal was significantly higher in cases than in controls (p 0.00001).

\section{CONCLUSION}

This study showed that delivery conducted by untrained persons is a risk factor for PID. Multiparity was not found to be a risk factor. For rural areas training of dais is important. The GOI has already started such training program for dais using strict aseptic techniques. This should be strengthened to ensure aseptic delivery.

Funding: No funding sources

Conflict of interest: None declared

Ethical approval: Not required

\section{REFERENCES}

1. Spencer $\mathrm{TH}$, Umeh PO, Irokanulo E, Baba MM, Spencer BB, Umar AI, et al. Bacterial isolates associated with pelvic inflammatory disease among female patients attending some hospital in Abuja, Nigeria. Afr J Infect Dis. 2014;8:9-13.

2. Davis B, Turner K, Ward H. Risk of pelvic nflammatory disease after Chlamydia infection in a prospective cohort of sex workers. Sex Transm Dis. 2013;40:230-4.

3. Herzog SA, Altaus CL, Heijne JC, Qakeshott P, Kerry S, Hay P, et al. Timing of progression from Chlamydia trachomatis infection to pelvic inflammatory disease: A mathematical modeling study. BMC Infect Dis. 2012;12:187.

4. Schindlbeck C, Dziura D, Mylonas I. Diagnosis of pelvic inflammatory disease (PID): Intra-operative finding and comparison of vaginal and intraabdominal cultures. Arch Gynecol Obstet. 2014;289:1263-9.

5. Paavonen J, Molander P. Pelvic inflammatory disease. In Robert W. Shaw, W. Patrick Soutter, 
Stuart L. Text book of Gynecology. Stanton. China: Churchill Living Stone; 2003:894.

6. Pachauri S. Defining a reproductive health package for India: A proposed Framework. Regional Working Paper No 4 The Population Council; 1995.

7. Tolu Oyelowo DC. Pelvic Inflammatory Disease. In: Mosby's Guide to Women's Health. 2007:68-71. 8.

8. Epi_Info, Version 6.04_d. A word processing, Database, and Statistical Programme for Public Health on IBM-compatible Microcomputers. Centers for Disease Control and Prevention. Atlanta, Georgia, USA Developed by Dean AG, Coulombier D, Brendel KA, Smith DC, Burton AG, Dicker RC, et al. 2001.

9. Duncan ME, Tibaux G, Pelzer A, Reimann K, Peutherer JF, Simmonds P, et al. First coitus before menarche and risk of sexually transmitted disease. Lancet. 1990;335(8685):338-40.
10. Eschenbach DA. Prospective study of Pelvic inflammatory-disease by clinical criteria. Obstet Gynecol. 1950;55:1485-525.

11. Lee NC, Rubin GL, Grimes DA. Measures of sexual behavior and the risk of pelvic inflammatory disease. Obstet Gynecol. 1991;77(3):425-30.

12. Beerthuizen RJ. Pelvic inflammatory disease in intrauterine device users. Eur J Contracept Reprod. Health Care 1996;1(3):237-43.

13. Sweet RL, Draper DL, Hadley WK. Etiology of acute salpingitis: influence of episode number and duration of symptoms. Obstet Gynecol. 1981;58(1):62-8.

Cite this article as: Pandey S, Pandey R. Correlation of PID and multiparity: a case control study. Int J Reprod Contracept Obstet Gynecol 2017;6:897-900. 